\title{
Hypotensive Effect of Butein via the Inhibition of Angiotensin Converting Enzyme
}

\author{
Dae Gill Kang, ${ }^{a}$ Yun Cheol KIm, ${ }^{b, c}$ Eun Jin Sohn, ${ }^{a}$ Yun Mi LeE, ${ }^{a}$ An Sook LeE, ${ }^{a}$ Ming Hao YIn, ${ }^{a}$ and \\ Ho Sub LEE*,a,b \\ ${ }^{a}$ Department of Herbal Resources, Professional Graduate School of Oriental Medicine, Wonkwang University; ${ }^{b}$ Medicinal \\ Resources Research Center (MRRC), Wonkwang University; and ${ }^{c}$ College of Pharmacy, Wonkwang University; Iksan, \\ Jeonbuk, 570-749, Republic of Korea. Received March 28, 2003; accepted May 22, 2003
}

\begin{abstract}
Butein $\left(3,4,2^{\prime}, 4^{\prime}\right.$-tetrahydroxychalcone), a plant polyphenol, has been known to elucidate endothelium-dependent vasodilation. In the present study, the hypotensive effect of butein and its possible mechanism, especially an angiotensin converting enzyme (ACE) inhibitory effect, were investigated. Intravenous injection of butein lowered the arterial blood pressure of anesthetized rats in a dose-dependent manner. The plasma ACE activities were significantly inhibited by the addition of butein in a dose-dependent manner, the $\mathrm{IC}_{50}$ value of which was $198 \mu \mathrm{g} / \mathrm{ml}\left(730 \mu_{\mathrm{M}}\right)$. Moreover, angiotensin I-induced contraction was markedly attenuated by prior exposure of endothelium-intact aortic rings to butein, but angiotensin II-induced contraction was not altered. These results suggest that butein has a hypotensive effect, at least in part, via the inhibition of angiotensin converting enzyme.
\end{abstract}

Key words butein; angiotensin converting enzyme (ACE); blood pressure

The renin-angiotensin system (RAS) plays a dominant role in the regulation of the water-electrolyte balance and blood pressure. Excessive activation of this system has been considered to be a main cause of renovascular hypertension. Among the several RAS components, angiotensin converting enzyme (ACE) is the most important regulatory site. ACE is a dipeptidyl carboxypeptidase (EC 3.4.15.1) that inactivates the vasodepressor compound bradykinin and catalyzes the production of the potent vasoconstrictor and growth-promoting substance angiotensin II by the removal of the carboxyterminal dipeptide of angiotensin I. It has been well demonstrated that the inhibition of ACE lowers blood pressure in animal models and in humans with various types of hypertension. ${ }^{1)}$ Moreover, the importance of ACE inhibitors is well established in the chronic treatment of various cardiovascular diseases such as congestive heart failure, ${ }^{2)}$ myocardial infarction, ${ }^{3)}$ and diabetic nephropathy. ${ }^{4)}$ Therefore, the synthetic ACE inhibitors such as captopril, enalapril, lisinopril, and temocapril are widely used in the clinic for the treatment of cardiovascular diseases. ${ }^{5)}$ Thus, the screening and development of ACE inhibitors would be beneficial in the treatment of cardiovascular diseases. In fact, in vitro screenings for the detection of ACE inhibitors in ethnobotanical sources have been widely performed, ${ }^{6,7)}$ and several classes of plant-derived secondary metabolites have been described as ACE inhibitors. ${ }^{8)}$

Butein (3,4,2',4'-tetrahydroxychalcone) (Fig. 1), a plant polyphenol, is one of the major active component of the stems of Rhus verniciflua have been traditionally used for the treatment of pain, parasites, and thrombotic disease in Korea.

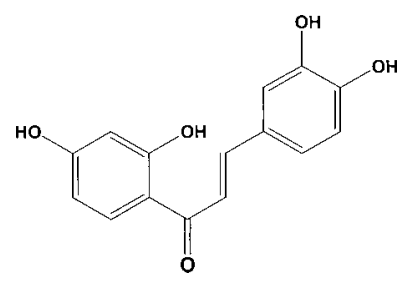

Fig. 1. Chemical Structure of Butein
The pharmacological actions of butein have previously been demonstrated in several studies. These beneficial effects include antioxidant and anti-inflammatory activities, ${ }^{9,10)}$ elicitation of endothelium-dependent vasodilation, ${ }^{11)}$ induction of apoptosis, ${ }^{10,12)}$ inhibition of protein kinase activity ${ }^{13,14)}$ and glutathione reductase, ${ }^{15)}$ and inhibitory activity against HIV-1 protease. ${ }^{16)}$ In addition to these actions, it has been reported that butein ameliorates glomerulonephritis in rats. ${ }^{17)}$ In the present study, we examined the ACE inhibitory activity of butein in vitro and in vivo to elucidate the mechanism of its hypotensive effect.

\section{MATERIALS AND METHODS}

Materials Butein, angiotensin I, angiotensin II, and all assay agents including Hip-His-Leu, His-Leu were purchased from Sigma Chemical Company (St. Louis, MO, U.S.A.).

Measurement of Arterial Blood Pressure Male Sprague-Dawley rats (approximately $300 \mathrm{~g}$ ) were anaesthetized with sodium pentobarbital (i.p. $50 \mathrm{mg} / \mathrm{kg}$ ). The femoral artery and vein were cannulated for the measurement of blood pressure and the intravenous administration of butein, respectively. Following a stabilization period of $20 \mathrm{~min}$, arterial blood pressure was recorded with a pressure transducer connected to a Narco physiograph (model MKIII-P, Houston, TX, U.S.A.) with injection butein dissolved in saline.

Determination of ACE Activity ACE activity was determined in rat plasma using the method described by Santos et al. ${ }^{18)}$ Briefly, plasma $(10 \mu \mathrm{l})$ was incubated with 490 or $480 \mu \mathrm{l}$ of assay buffer containing $5 \mathrm{mmol} / \mathrm{l}$ Hip-His-Leu in $40 \mathrm{mmol} / 1$ sodium borate buffer and $0.9 \mathrm{~mol} / 1 \mathrm{NaCl}$, and $10 \mu \mathrm{l}$ of butein, $\mathrm{pH} 8.3$, for $15 \mathrm{~min}$ at $37^{\circ} \mathrm{C}$. The reaction was stopped by the addition of $1.2 \mathrm{ml}$ of $3.4 \mathrm{~N} \mathrm{NaOH}$. The product, His-Leu, was measured fluorimetrically at $365 \mathrm{~nm}$ excitation and $495 \mathrm{~nm}$ emission with a fluorescence spectrophotometer (Hitachi, model F-2000, Tokyo) as follows. One hundred microliters of $o$-phthalaldehyde $(20 \mathrm{mg} / \mathrm{ml})$ in methanol was added into the reaction solution for $10 \mathrm{~min}$ and then the 
solution was acidified with $200 \mu \mathrm{l}$ of $3 \mathrm{~N} \mathrm{HCl}$ and centrifuged at $3000 \mathrm{rpm}$ for $10 \mathrm{~min}$ at room temperature. To correct the intrinsic fluorescence of the plasma, a time zero blank was prepared by adding plasma after $\mathrm{NaOH}$ treatment. The $50 \%$ inhibitory concentration $\left(\mathrm{IC}_{50}\right)$ was determined in butein using linear regression analysis.

Preparation of Rat Aorta Healthy male Sprague-Dawley rats, weighing $250-300 \mathrm{~g}$, were sacrificed by decapitation. The thoracic aortae of these rats were rapidly and carefully dissected and placed into ice-cold Krebs solution ( $\mathrm{pH}$ 7.4) containing $118 \mathrm{mmol} / \mathrm{l} \mathrm{NaCl}, 4.7 \mathrm{mmol} / 1 \mathrm{KCl}, 1.1$ $\mathrm{mmol} / 1 \mathrm{MgSO}_{4}, 1.2 \mathrm{mmol} / 1 \mathrm{KH}_{2} \mathrm{PO}_{4}, 1.5 \mathrm{mmol} / 1 \mathrm{CaCl}_{2}, 25$ $\mathrm{mmol} / 1 \mathrm{NaHCO}_{3}$, and $10 \mathrm{mmol} / 1$ glucose. The aortae were removed free of connective tissue and fat, and then cut into rings approximately $3 \mathrm{~mm}$ wide. All dissecting procedures were done with extreme care to protect the endothelium from inadvertent damage. Endothelial integrity or functional removal was verified by the presence or absence, respectively, of a relaxant response to $3 \times 10^{-6} \mathrm{M}$ acetylcholine.

Record of Isometric Vascular Tone The aortic rings were suspended in a tissue bath containing Krebs solution at $37^{\circ} \mathrm{C}$ while being continuously bubbled with $95 \% \mathrm{O}_{2}-5 \%$ $\mathrm{CO}_{2}$ ( $\mathrm{pH}$ 7.4). The baseline load placed on the aortic rings was $1.5 \mathrm{~g}$, and the changes in isometric tension were recorded using a force-displacement transducer (Grass FT 03, Quincy, MA, U.S.A.) connected to a Grass polygraph recording system (Model $7 \mathrm{E}$ ). In the first set of experiments, the aortic rings were contracted with phenylephrine $\left(1 \times 10^{-6} \mathrm{M}\right)$ to obtain a maximal response. Once the maximal response to phenylephrine had been obtained, the aortic rings were washed every 20 min with Krebs solution until the tension returned to the basal level. The rings were exposed to butein for $10 \mathrm{~min}$, and then aortic contraction was carried out by the addition of angiotensin $\mathrm{I}\left(1 \times 10^{-7} \mathrm{M}\right)$ or angiotensin II $\left(1 \times 10^{-7} \mathrm{M}\right)$. The effect of vehicle $(0.9 \% \mathrm{NaCl}$ solution $)$ was also tested. After each test, the aortic rings were washed three times with fresh Krebs solution and allowed to equilibrate for $30 \mathrm{~min}$.

Statistics The results are expressed as the mean \pm S.E.M. Significant differences between the groups means were determined using Student's $t$-test.

\section{RESULTS}

Effect on Arterial Blood Pressure in Anesthetized Rats Typical responses to butein on arterial blood pressure are shown in Fig. 2. Intravenous injection of butein induced immediate and dose-dependent decreases in the arterial blood pressure in anesthetized normotensive rats.

Effect on ACE Activity The plasma ACE activities were significantly inhibited by the addition of butein in a dose-dependent manner (Fig. 3). The concentration of the fifty percent inhibition $\left(\mathrm{IC}_{50}\right)$ value of butein for $\mathrm{ACE}$ was $198 \mu \mathrm{g} / \mathrm{ml}$ (730 $\mu \mathrm{M})$.

Effect on Angiotensin I or Angiotensin II-Induced Vasoconstriction To support this result, the inhibitory effect of butein on the angiotensin I-induced vasoconstriction was examined. In the endothelium-intact aortic rings, angiotensin I-induced contraction was markedly attenuated by prior exposure of the aortic rings to butein in a dose dependent manner (Fig. 4). The maximum contraction by an-

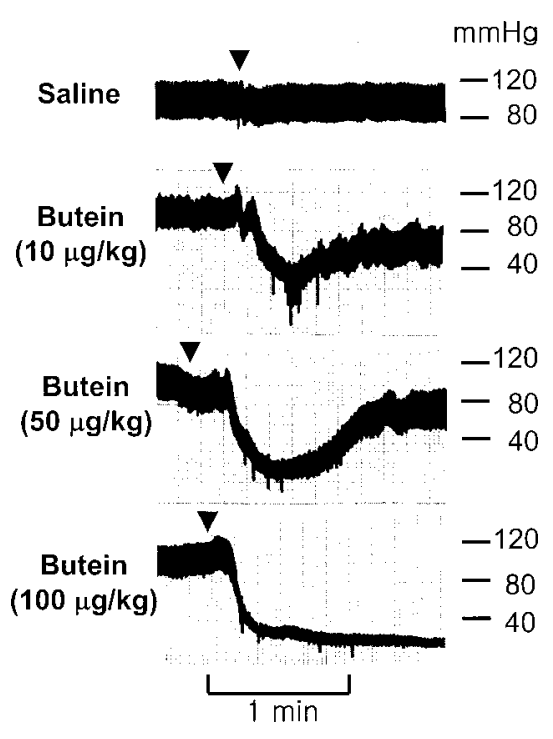

Fig. 2. A Typical Recording of Blood Pressure Changes Induced by Intravenous Injection of Butein in Anesthetized Rats

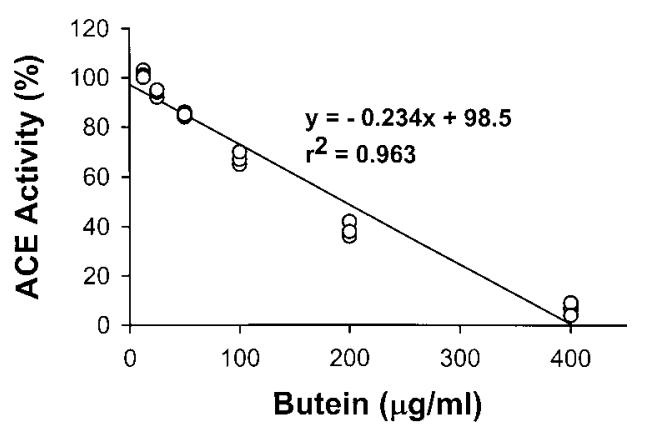

Fig. 3. Dose-Dependent Inhibition of Angiotensin Converting Enzyme Activities by Butein

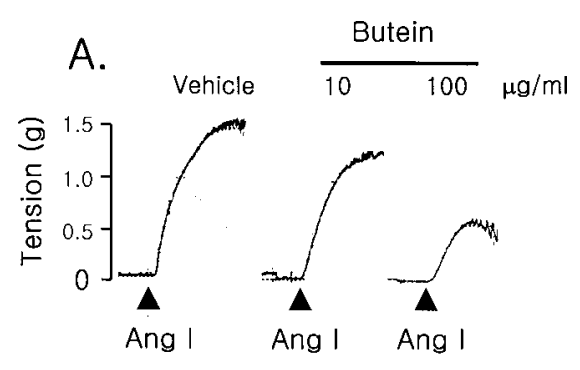

B.

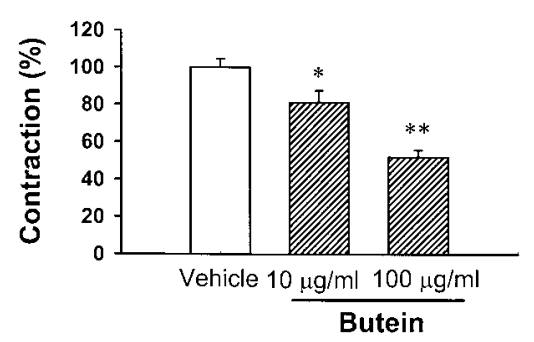

Fig. 4. A Typical Recording of the Inhibition of Butein on Vascular Contraction Induced by Angiotensin I $\left(1 \times 10^{-7} \mathrm{M}, \boldsymbol{\Delta}, \mathrm{A}\right)$ and Statistical Analysis of Relative Contraction (B)

Each vale represents the mean \pm S.E. ( $n=4$, each experiment). 


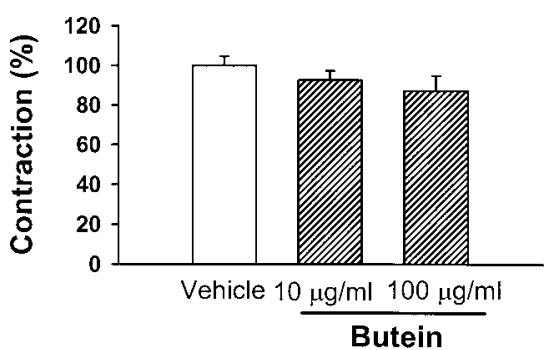

Fig. 5. Effect of Butein on Vascular Contraction Induced by Angiotensin II $\left(1 \times 10^{-7} \mathrm{M}\right)$

Each value represents the mean \pm S.E. $(n=4$, each experiment).

giotensin I was approximately $60 \%$ compared with full contraction induced by phenylephrine $\left(1 \times 10^{-6} \mathrm{M}\right)$. Angiotensin I (100 nM)-induced contraction was attenuated to approximately $81 \%$ compared with that of vehicle by prior exposure of aortic rings to $10 \mu \mathrm{g} / \mathrm{ml}$ of butein. Angiotensin I-induced contractions were blocked by $48 \%$ compared with vehicletreated group when the aortic rings were exposed to $100 \mu \mathrm{g} / \mathrm{ml}$ of butein. However, there were no significant differences in angiotensin II-induced vasoconstriction between the vehicle and 10 or $100 \mu \mathrm{g} / \mathrm{ml}$ butein-treated groups (Fig. $5)$.

\section{DISCUSSION}

The present study investigated whether butein could induce a lowering of blood pressure via the inhibition of ACE in rats. The arterial blood pressure was immediately decreased in a dose-dependent manner in anesthetized normotensive rats by the administration of butein. Moreover, the ACE activities were significantly inhibited by the addition of butein in a dose-dependent manner. To support this result, the inhibitory effect of butein on angiotensin I-induced vasoconstriction was examined. In the endothelium-intact aortic rings, angiotensin I-induced contraction was markedly attenuated by prior exposure of the aortic rings to butein in a dose dependent manner. However, butein had no discernible effects on angiotensin II-induced vasocontriction profiles in the aorta. These findings suggest that butein lowered arterial blood pressure via an ACE inhibitory effect.

In fact, several classes of ACE inhibitory compounds derived from plant have been identified, for examples hydrolysable tannins, ${ }^{19)}$ flavonoids, ${ }^{20)}$ xanthones, ${ }^{21)}$ fatty acids, ${ }^{22)}$ terpenoids, ${ }^{23)}$ peptides, ${ }^{24)}$ procyanidins, ${ }^{25)}$ and caffeoylquinic acid derivatives. ${ }^{26}$ )

ACE is a zinc-containing peptidyl dipeptide hydrolase. ${ }^{27)}$ The active site of ACE is known to consist of three parts; a carboxylate binding functionality such as the guanidinium group of Arg, a pocket that accommodates a hydrophobic side chain of C-terminal amino acid residues, and zinc ion. The zinc ion coordinates to the carbonyl group of the penultimate peptide bond of the substrate, whereby the carbonyl group becomes polarized and is subjected to a nucleophilic attack. Therefore, some flavonoids ${ }^{20)}$ were suggested to show in vitro activity via the generation of chelate complexes within the active center of ACE. Free hydroxyl groups of phenolic compounds are also suggested to be important structural moieties to chelate the zinc ions, thus inactivating the ACE activity. ${ }^{21)}$ Since butein contains aromatic hydroxyl groups, this hydroxyl groups may show an ACE inhibitory activity due to the generation of chelate complexes with zinc ions within the active center of ACE.

It is likely, therefore, that the butein-induced hypotensive effect may be, at least in part, due to an ACE inhibitory effect of butein.

Acknowledgements This study was supported by the Brain Korea 21 Project (2002) and a grant from the Oriental Medicine R\&D Project (HMP-00-CO-03-0003) of the Ministry of Health \& Welfare, Republic of Korea, and MRRC of Wonkwang University.

\section{REFERENCES}

1) Lee M. A., Paul M., Bohm M., Ganten D., Am. J. Cardiol., 70, 12C19C (1992).

2) Carson P. E., Am. Heart J., 140, 361-366 (2000).

3) Shlipak M. G., Browner W. S., Noguchi H., Massie B., Frances C. D., McClellan M., Am. J. Med., 110, 425-433 (2001).

4) Hebert L. A., Falkenhain M. E., Nahman N. S., Jr., Cosio F. G., O'Dorisio T. M., Am. J. Nephrol., 19, 1-6 (1999).

5) Sleight P., Curr. Cardiol. Rep., 3, 511-518 (2001).

6) Nyman U., Joshi P., Madsen L. B., Pederses T. B., Pinstrup M., Rajasekharan S., George V., Pushpangadan P., J. Ethnopharmacol., 60, 247-263 (1998).

7) Duncan A. C., Jager A. K., van Stan J., J. Ethnopharmacol., 68, 6370 (1999).

8) Kameda K., Takaku T., Okuda H., Kimura Y., Okuda T., Hatano T., J. Nat. Prod., 50, 680-683 (1987).

9) Chan S. C., Chang Y. S., Wang J. P., Chen S. C., Kuo S. C., Planta Med., 64, 153-158 (1998).

10) Lee J. C., Lim K. T., Jang Y. S., Biochim. Biophys. Acta, 1570, $181-$ 191 (2002).

11) Yu S. M., Cheng Z. J., Kuo S. C., Eur. J. Pharmacol., 280, 69-77 (1995).

12) Iwashita K., Kobori M., Yamaki K., Tsushida T., Biosci. Biotechnol. Biochem., 64, 1813-1820 (2000).

13) Yang E. B., Zhang K., Cheng L. Y., Mack P., Biochem. Biophys. Res. Commun., 245, 435-438 (1998).

14) Yang E. B., Guo Y. J., Zhang K., Chen Y. Z., Mack P., Biochim. Biophys. Acta, 1550, 144-152 (2001).

15) Zhang K., Yang E. B., Tang W. Y., Wong K. P., Mack P., Biochem. Pharmacol., 54, 1047-1053 (1997).

16) Xu H. X., Wan M., Dong H., But P. P., Foo L. Y., Biol. Pharm. Bull., 23, 1072-1076 (2000).

17) Hayashi K., Nagamatsu T., Honda S., Suzuki Y., Jpn. J. Pharmacol., 70, 55-64 (1996).

18) Santos R. A., Krieger E. M., Greene L. J., Hypertens., 7, 244-252 (1985).

19) Ueno H., Hori S., Nishi Y., Shogawa H., Kawasaki M., Suzuki S., Hayashi T., Arisawa M., Shimizu M., Yoshizaki M., Morita N., J. Nat. Prod., 51, 357-359 (1988).

20) Wille P. R., Ribeiro-do-Valle R. M., Simoes C. M., Gabilan N. H., Nicolau M., Phytother. Res., 15, 444-446 (2001).

21) Chen C. H., Lin J. Y., J. Nat. Prod., 55, 691-695 (1992).

22) Morota T., Sasaki H., Chin M., Sato T., Katayama N., Fukuyama K., Mitsuhashi H., Shoyakugaku Zasshi, 41, 169-173 (1987).

23) Morigiwa A., Kitabatake K., Fujimoto Y., Ikekawa N., Chem. Pharm. Bull., 34, 3025-3028 (1986).

24) Kinoshita E., Yamakoshi J., Kikuchi M., Biosci. Biotechnol. Biochem., 57, 1107-1110 (1993).

25) Wagner H., Elbl G., Planta Med., 58, 297 (1992).

26) Oh H., Kang D. G., Lee S., Lee H. S., J. Ethnopharmacol., 83, 105108 (2002).

27) Strittmatter S. M., Snyder S. H., Mol. Pharmacol., 29, 142-148 (1986). 